\title{
Informe etnográfico del viaje a Huarochirí
}

\section{Introducción}

Este viaje se efectuó por invitación de la Alcaldesa de la provincia de Huarochirí, en relación a las acciones de promoción para conocer las riquezas naturales, arqueológicas, históricas y antropológicas de los distritos sureños que, luego posibiliten proyectos de investigación, programas de desarrollo o actividades educativas que promuevan conocer y elevar la identidad cultural de los pueblos, orientados a promover, con propiedad y autoestima, el turismo de la región cisandina de Lima. Lo que fue aceptada por el Director de la EAP de Antropología y nos delegó: al profesor Sabino Arroyo Aguilar y a los alumnos Alex Azaña Obregón (03150096), Alonso Burgos Cisneros (05150204) y David Gutiérrez Ruiz (04150224).

Para el mejor acopio de la información etnográfica de los distritos sureños de Huarochirí, realizado entre los días del 4 al 8 de abril de 2008, se organizó en tres rubros: la actividad productiva se encargó a Alonso, culto a los santos patrones a Alex, y David se dedicó a los mitos andinos. Fruto de dicho viaje y acopio se adelanta hoy como diagnosis para su ulterior investigación sistemático, bajo convenio con las autoridades distritales de la provincia.

\section{Economía agropecuaria}

Alonso Burgos Cisneros

\section{Distrito Santiago de Anchucaya}

1.1. Actividad agroganadera. Hay unos 650 comuneros con un aproximado de 3 a 4 hectáreas de tierras por familia, que se dedican a las labores agrícolas con la yunta, chakitaklla, lampa, pico y barreta; mediante el uso limitado de los fertilizantes e insecticidas; y producen principalmente papa, oca, mashua, habas, trigo y maíz para el autoconsumo. En la ganadería, cada familia cuenta con 3 a 4 cabezas de ganado vacuno lechera, cuyo queso derivado lo destinan para el mercado local y de Lima.

1.2. Artesanías. Existen tres telares artesanales y tres familias de tejedores en todo el pueblo, que elaboran pañolones, frazadas, ponchos, alforjas, mantas y rebozos para el uso de los pobladores de la localidad. 


\section{Distrito de Sangallaya}

Actividad agropecuaria. Hay unos 200 familias que producen maíz, habas y sobre todo tienen huertos frutales de manzana, níspero y duraznos, con instrumentos como la chakitaklla, lampa, pico y barreta; mediante el uso de los fertilizantes e insecticidas. En la ganadería cuentan con vacunos mejorados que proveen carne y queso para comercializar en el mercado de Lima.

San Pablo de Quiripa es uno de los anexos de Sangallaya con unos 80 comuneros que se dedican a la fruticultura, como los de Huancata y de Alloca.

\section{San Lorenzo de Quinti}

Actividad agropecuaria. Los 800 comuneros se dedican a la producción de la papa, arvejas, maíz, trigo, cebada, las habas, olluco y la oca con instrumentos de producción tradicional, mediante el uso limitado de fertilizantes y de insecticidas. Mayormente es para el consumo propio y local, mientras la ganadería es básicamente criolla, cuyo queso derivado se comercializa en el mercado de Lima

\section{San Pedro de Huancaire}

En la actividad agroganadera se dedican unos 70 comuneros con instrumentos tradicionales, común a la región, también los tubérculos como la papa, olluco, mashua, oca, trigo, arvejas y las habas para el consumo familiar; en cambio el queso derivado del vacuno es para el mercado regional.

\section{Algunas observaciones generales:}

1. En las comunidades de altura de clima frío (Santiago de Anchucaya, San Lorenzo de Quinti, San Pedro de Huancaire) predomina el cultivo de tubérculos como la papa, oca y olluco. En las comunidades bajas de clima templado (Sangallaya, San Pablo de Quiripa y Huancan) se cultivan frutas como la manzana, durazno y el níspero.

2. Los instrumentos de producción agraria son tradicionales a excepción de algunas insecticidas y fertilizantes químicos; esto por dos razones: Primero, la geografía accidentada no permite maquinaria pesada (tractores, segadoras, etc.) y, segundo, los bajos recursos imposibilitan la tecnificación.

3. La mayoría de la producción agropecuaria es para el autoconsumo. Mientras la carne y queso del ganado vacuno, ovino y caprino es para el mercado regional de Lima. Aunque en Quiripa y toda la parte baja están ampliando crianza de pollos y de cuy para la gastronomía regional. Mientras en la parte alto andina, se destina la crianza de los camélidos para comercializar la fibra de alpaca en el mercado nacional.

4. Sin embargo, existe la desnutrición crónica de los niños en todas las comunidades, porque la carne y leche es sólo para el mercado.

5. En todas las comunidades hay artesanía textil, pero los más representativos están en Santiago de Anchucaya.

6. La mayoría de las comunidades ofrecen potencial turístico por sus recursos naturales, arqueológicos y actividades festivas de la champería, cultos santorales y la latencia de los mitos andinos de origen precolombino, como de Pariaqaqa.

7. La mayoría de la mano de obra joven migra a Lima en busca de trabajo y educación y sólo se mantienen los mayores y niños, principalmente.

8. No existe un real apoyo del Estado a estas comunidades alto andinas para reactivar sus productividades como también sus recursos para el turismo. Recién están tomando conciencia las autoridades locales y provinciales para su respectiva atención y su ulterior desarrollo autosostenido. 


\section{HUAROCHIRÍ: MITOS, LEYENDAS Y RUINAS ${ }^{1}$}

\section{David Gutiérrez Ruiz}

\section{La resistencia de los antiguos pueblos de huarochirí}

Cuando los españoles arriban a la región de Huarochirí encuentran gran resistencia por los antiguos pueblos y ayllus, dirigidos por sus respectivos jefes como la Mamashangay de Sangallaya, Chaupimaria que hoy es la comunidad campesina de Huarochirí, Huancashuaman del ayllu de Suni, Huanhuarirumo del ayllu de Llambilla y el señor Achaysicha del ayllu de Lupo. Todos dirigidos por Huancashuman, quien organiza la resistencia indicando que ningún español quede vivo: por la retaguardia, en Chuicoto, a cargo de Chaupimaria y por la parte alta el jefe de Suni con las galgadas; por esta parte por Huanhuarirumo. Al final ningún español quedó vivo y suponiendo que llegaba vivo al fondo de quebrada, entonces, de Mamashangay se encargaba de darle la estocada final. Tal como planearon resultó y esta noticia salió a Lima, el triunfo de los nativos. Aunque, paralelamente hay una rivalidad con Francisco Inga, quien pensaba también hacer la revolución y ser el primero en el grito de la Libertad, a nivel provincial y a nivel regional; mientras el fin de Huancashuaman no era ser el héroe o salir en los titulares, sino, simplemente defender sus tierras.

En la segunda versión vienen y toman de sorpresa desde la retaguardia, capturando a los jefes, menos a Huancashuaman, por lo que dijeron: "Nosotros no hemos querido enfrentarnos a los blancos, ha sido Huancashuaman, él es el que nos dijo vamos a enfrentarnos, porque ellos nos van a matar, preferible nosotros matamos a ellos, él es el que nos mintió”. Todos le echaron la culpa por estrategia, pensando salvar su pellejo, “Qué más saben ustedes de Huancashuaman?", los soldados españoles les preguntaron; ellos hablaron todo de Huancashuaman, muy bien "Algo más tienen que decir" -"no, nada más, eso no mas sabemos" -“ya muy bien, ¡soldados! Dale muerte a estos, porque ya hablaron todo, para que me sirve esta gente, ya, las cabezas abajo" y lo mataron.

Huancashuaman desaparece y de ahí nos queda dos hipótesis: unos dicen que Huancashuaman, para no caer en manos de los españoles, toda su familia podía enterrarse porque arriba hay un túnel, había, ahora ya está cerrado, había un túnel que no se sabe dónde va a definir y en la actualidad existe otro túnel en Sangallaya, nadie sabe dónde va a salir, pero según el relato de los antiguos saldría a Pachacamac; y otros dicen que se dio a la fuga. Entonces entran en discusión: Huancashuaman era un hombre tan duro, tan macho (que) cómo se iba a enterrar, cómo se iba a fugar, los fugitivos son cobardes. La discusión continúa y dicen que Huancashuaman salió de acá, de este lugar con la finalidad de reorganizarse en otro lugar y regresar y tomar su poder de esta zona, aunque hay un comentario de que por la parte norte de Ayacucho hay un pueblito que no recuerdo el nombre, en ese pueblito todos se apellidan Cashuaman, posiblemente sean nuestros descendientes que estaban allá, ahora viven allá, con la mentalidad de agrupar más gente y venir acá a retomar sus poderes, pero parece que no pudieron recolectar más gente y allí no más quedaron, entonces, eso todavía nos queda tema de investigación.

Entonces ya con la muerte de todos nuestros jefes, de todos nuestros lideres, los españoles fundan este pueblo con el nombre de Huarochirí. Esto es algo curioso, de Lima sale la orden de formar acá el pueblo de Santa María, nada más, Santa María ¿Por qué? Para llegar a toda esta zona primero tienen que llegar acá y acá es como el corazón, de aquí

1 Estos relatos fueron narrados por don Arnaldo Tello Macavilca de 55 años. 
se reparte para todos los lugares. Entonces fundan como la ciudad de Santa María, pero en el trayecto sufren el frío, porque a partir de junio y julio es época de la helada y como los españoles venían con su pantaloncito corto, su calzoneta, algo así hablaban y aquí a eso lo llamaban "Huaro" en Kauki, y Chiri es frío: huaro-chirí. Entonces nos cuentan, que de allí podría provenir el nombre de Huarochirí. Hay otro investigador (se refiere a sus abuelos y bisabuelos) que dijo que nada que ver con eso, porque huaro también es quechua y significa huaro $=$ puente; pero ningún puente se pasa para llegar a Huarochirí, pero si nosotros nos ubicamos frente al pueblo se ve como la forma de un puente colgante, y para mí que eso es lo más acertado: huaro-chiri, chiri por el frió, tanto en kauki como en quechua chiri es frío, entonces de allí sale el nombre de Huarochirí.

Ahora ¿este pueblo cómo se forma? En la rendición, ya que todos los jefes los invitan a congregarse, a bajar de sus ruinas arqueológicas que tienen, de allí vienen a vivir acá. Lo primero trazan el pueblo: la plaza, la iglesia y el cementerio y de allí dividieron en forma de aspa, esta parte central lo ocupaban todos los que venían de Suni, en la parte sur, a la derecha, todos los que vivían en Mamachangay y en la parte izquierda los de Chuicoto y de Chaupimaria, que hoy día es Huarochirí, y del lado oeste la comunidad de Llambilla y para el este, lado de Chamoca, es la comunidad de Lupo; y prueba de ello es aún tienen sus locales comunales en cada uno de estos lugares; o sea, que toda la gente que vivían en sus ayllus bajaron con todo a poblar acá.

\section{Mito de Pariacaca}

Desde antes hemos escuchado que Pariacaca había sido un apu, apu de las aguas. Él vivía siempre enamorado de la princesa Chayculla, el cerro más alto que está al fondo, ese es Chayculla. Bueno, la princesa Chayculla no lo aceptó, porque Pariacaca era un hombre muy especial, tenía mucho poder, pero como tenía demasiado poder el hombre se vestía demasiado simple, pobre, que cualquiera veía diría que es un mendigo y a él le encantaba desempeñar el papel de mendigo; $y$, a la princesa Chayculla le ofreció agua a cambio de su amor, le llevó en un cantarito y resulta que no lo recibió, no lo aceptó ni tampoco lo recibió. Así, Pariacaca se fue caminando, se fue donde otra princesa, Wichuca de Santo Domingo de los Olleros; tampoco aceptó la princesa Wichuca, pues las chicas eran simpáticas, altas, guapas y él todo andrajoso.

Así el hombre, triste, cabizbajo, fracasado en el amor retornaba y se encuentra en el trayecto con una mujer, con una doncella que estaba tejiendo su manta, era Cavillaca; era la princesa, era la ñusta de familia noble. Entonces él (Pariacaca) le ofrece su amor, le dijo que no, y como Pariacaca tenía poder la engaña: Cavillaca, al árbol tenía que poner así como un estacón grande y ese estacón era una fruta que se llamaba lúcuma, y ella trabajando hace fuerza y cae una lúcuma, madurita estaba y ella se la comió y según cuenta la leyenda, allí estuvo Pariacaca, le engendró un hijo y ya transcurrido los nueve meses, esta ñusta preocupada (por saber) quién podía ser el padre, si ella nunca tuvo ningún enamorado y menos iba a tener relación, de donde va a nacer esa criatura; así llamó a todos los brujos para saber cómo podía hacer y los brujos daban la conclusión que es de un dios y le aconsejan que llame a todos los dioses y sabrá cuál de ellos es. La criatura tendría seis o siete meses, ya gateaba, entonces llama a todos los dioses, esta chica se arregló bien, ya toda simpaticona estuvo y todos querían estar con ella y todos llamaban al bebe "ven, ven a mí, a mí" y (el bebe) iba a uno y nada que ver, iba al otro y nada que ver y así hasta el final y el último era el andrajoso que estaba hasta las patas y ahí se levanta el bebe y se abraza de Pariacaca. 
Y Cavillaca dice: ¡No! Yo estoy de acuerdo con cualquiera menos con él, no, no puede ser". Coge al hijo y se va despavorida, camino sin rumbo, y los demás dioses le increpan a Pariacaca "oye, como haces esas cosas, al menos nosotros estamos aptos, pero ¿tú? Al menos preséntate mejor, al menos para que te acepten". Y en esas discusiones que estaba, así conforme has hecho el hijo, ahora tienes que responder; entonces, Pariacaca se anima y va al alcance, en el trayecto se encuentra con varios animales: encuentra a una serpiente que estaba bien paradita así tipo cobra y le dice: "Tú lo has visto a una mujer con un niño en el brazo" - "No, no lo he visto, pero si acaso ha estado pasando por acá no lo he visto" — "pues te maldigo, a partir de ahora te arrastrarás por el suelo", le dice y por eso dice que la culebra se arrastra; sigue su trayecto, se encuentra con el zorro: "Señor zorro le dice, tú has visto a una mujer con un hijo en el brazo" - "si" le dice -"muy bien, a qué distancia están?”-_¿distancia? no, la mujer se regresó” — “mentiroso, si el rastro da para abajo, por qué dices que se regresó?” y se ríe el zorro, “Te maldigo, a partir de hoy día, tu vivirás perseguido por los hombres, para alimentarte tendrás que robar, y por ese robo serás destinado a la muerte" por eso que el zorro tiene que vivir a escondidas y tiene que robar para alimentarse. Y sigue así su ruta, se encuentra una palomita, y a la palomita le dice "¿has visto una mujer con un niño?” — “lleva distancia” le dice, _ “"podría alcanzarla?” —_"Sí, le dice, si usted acelera alcanza" - “te bendigo palomita, a partir de hoy día tu vivirás feliz y tu trinar será lindo en el amanecer y serás fiel para tu pareja y tu pareja será fiel para ti”, le dio su bendición y continúo, y así cuando el ve, ya llegando a Pachacamac, llegando a Lurín, a lo lejos ve a la mujer, Pariacaca va al alcance y la mujer ¿qué hace? Para no caer en manos de Pariacaca se arroja al mar, los dos con el bebe, al arrojarse en el mar, queda convertida en una isla y la hija en la otra isla más pequeñita, frente a Pachacamac (ruinas) y en Lurín hoy sale el agua, el agua que llevaba Pariacaca, un canal encantado, hay agua. Y cuentan los antiguos que ahí está la planta de la palla, la pakepuna, el ichu, todo eso existe allí y sale cantidad de agua que se va al mar, en Lurín y no es en Chilca. Luego Pariacaca regresó, nunca más pretendió a ninguna princesa ni a nadie y se fue a ocultarse a la cordillera, como era el dios de la aguas, ahí quedó. Por eso hay esperanza de que un día vaya a salir; entonces, será otra historia diferente, la segunda venida de Pariacaca, Cuniraya Pariacaca.

\section{El llanto de Toycoña}

Cuando Pariacaca llega a la fiesta, también como de costumbre disfrazado de mendigo, los señores de la puerta no le dejaron pasar, le botaron a pesar de que reclamaba haber sido invitado. Y sólo las huachacamas, mujeres que preparan la chicha, una de las huachacamas que se llamaba Toycoña se compadeció y le ofreció un poquito de chicha y Pariacaca agradece y le dice: "Toycoña, hijita, ven acá, tú eres la única que te has compadecido de mí, todos pasan con olorosas viandas y nadie se acuerda de mí, pero, tú eres la única que te has compadecido y te digo: Mañana temprano saca tus cositas lo que puedas llevar y te vas arriba a la cumbre de Matawa, yo voy a enviar un castigo, un castigo para que se acuerden toda esta gente. Y cuando escuches lo que escuches no voltees para nada, sin voltear usted camina y tú serás la única que te vas a salvar, no te olvides, mañana.

La señora decía "Ya, ya, ya señorcito ¿Yo voy a ser la única que me voy a salvar? Ya, ya, ya, gracias, gracias" lo tomó pues como una gracia; luego retornó a la fiesta: "bueno salud, salud” y siguió el baile hasta la amanecida. Al día siguiente ella se acordó "¿Será cierto, no será cierto? ¿Qué hago?” consulta a su familia, su familia le dice "Mamá y ¿quién te dijo eso?" - “no, había un mendigo un pordiosero allá afuera, todo hasta las patas estaba" - “ah, te engañaron”; la otra hermana le dice "no mamá ¿Qué tal es cierto? obede" — “vamos" le dice (la madre) — “no, usted no más anda, ya que usted no más quiere 
salvarse y la señora cumplió. Carga su quipicito, su cashmanta, es una manta grande, a la espalda y comenzó a caminar, cuando ella está subiendo el cerro empezó a nublarse, la neblina, más arriba empezó los truenos, rayos, más arriba empezó los ruidos, pues la lluvia era torrencial y cuando llega a esa parte de Chicre ya no soportó, voltió para atrás, al voltear ve que de todos esos cerros bajaban gran huayco y derechito fue a Huayquiuro, al pueblo, y todo eso lo desbarrancó y todo desapareció; y por ver todo eso, la señora quedó convertida en piedra. Me consta, yo llegue hasta el lugar, es una piedra chata que tiene dos agujeros y de allí brota agua (manantial) y dicen que esos son sus ojos, de la señora que llorando quedó convertida en piedra. 